\title{
Anthropology's Contribution to Public Health Policy Development
}

\author{
Dave Campbell*
}

Many people in the fields of medicine and public health do not understand the potential role that anthropology could play in the development of public health policy. The intention of this article is to provide readers with an understanding of the unique perspective that medical anthropology could contribute to informing public health policy decisions.

Socio-cultural anthropology has undergone significant theoretical and pragmatic changes over the past half-century. As a discipline, anthropology has been criticized for its role in imperial conquest. During colonial times, anthropologists often accompanied colonial explorers and military in order to facilitate their work, this is often referred to as 'the handmaiden era' in the history of anthropology's history. It is said that in this role, anthropologists gained the trust of natives using their linguistic proficiency and cultural awareness in order to assist the colonial state in the implementation of policies that ultimately led to further oppression and disempowerment (Pels and Salemind).

Such critiques, among others, have led to a significant redirection of anthropological thought and theory (Lewis). Social and cultural anthropology have turned towards a more critical, reflexive and holistic approach since that time. This 'reconstruction' of anthropology has resulted in an increase in criticism of those structures that had previously been assumed as 'right' and inherently 'good'. Scheper-Hughes writes about how social scientists have typically been blind to

*To whom correspondence should be addressed:

Dave Campbell

University of Calgary

Email: dcampbel@ucalgary.ca the unequal power relationships that have been harmful to informants. She calls for anthropologists to take a critical stance against such structural and institutional violence ("Coming to Our Senses").

Holism has also become an important hallmark of modern ethnography. Even the most basic concept of classic anthropology - culture has been rethought: "the modern view of culture is to stress the importance of always seeing it within its particular context... 'culture' cannot - and should never be - considered in a vacuum" (Helman 4,7). These fundamental changes in the broad discipline of socio-cultural anthropology have manifested themselves in each of its related sub-disciplines. This paper will examine these changes in the subdiscipline of medical anthropology, and particularly how these changes allow anthropology to make a contribution to public health policy development.

\section{RECENT EVOLUTION IN MEDICAL ANTROPOLOGY}

Anthropologists have been interested in medical practices for many decades; however, medical anthropology as a distinct subfield is a relative newcomer in the world of academia. The identification of the field of medical anthropology is generally attributed to William Caudill in his paper from 1953 entitled "Applied Anthropology in Medicine" (McElroy). Since that time Medical Anthropology has established a degree of independence from its parent discipline of social and cultural anthropology. Despite this autonomy, medical anthropology's disciplinary evolution has been greatly affected by the changes in social anthropology.

Ethnomedicine was the first of the subfields of medical anthropology to develop. The premises of this ideology was that gaining an understanding of local medical beliefs and practices could be 
beneficial in the provision of biomedical services to people in cultures where biomedicine was new and unknown. McElroy states that "Since the 1940s anthropologists have helped health care providers understand cultural differences in health behaviours" (3). Emphasis on this aspect of medical anthropology led to the development of the 'Explanatory Model' framework (Kleinman) and the benchmark volume 'Clinically Applied Anthropology' (Chrisman and Maretzki) among many others. These works focused heavily on doctor-patient interaction and how anthropology can be used as a tool in biomedicine.

This thinking was followed by a new wave of thinking that parallels the turn to reflexivity in social anthropology. In 1983, the term 'critical medical anthropology' was introduced (Baer). This new brand of medical anthropology was similar to the new reflexive social anthropology in that it was critical, holistic and inward looking: "it is the work of anthropology turned in upon ourselves, our own society" (Scheper-Hughes "Three Propositions" 196). Scheper-Hughes goes on to draw explicit parallels between colonial social anthropology and clinical medical anthropology by saying that medical anthropologists played a vital role in establishing the cultural hegemony of biomedicine. She calls for medical anthropologists to break with the field of western medicine and distance themselves in order to look back upon biomedicine objectively.

\section{ANTHROPOLOGY OF PUBLIC HEALTH}

Hans Baer defines critical medical anthropology as that which "aspires to merge theory and praxis in [a] desire to promote experiential health as opposed to the functional health associated with contemporary political economics around the world" (1011). Since the emergence of critically applied medical anthropology, several anthropologists have brought this brand of anthropological enquiry to the world of public health policy.

This is not to say that medical anthropology is new to public health. Anthropologists have been involved in public health for many years. However, prior to Critical Medical Anthropology (CMA), many medical anthropologists played the role of 'cultural brokers' (Scheper-Hughes "Three Propositions"). They were often involved in mediating between populations and policy makers in much the same way in which medical anthropologists mediated between clinician and patient, or social anthropologists between colonizer and colonized. Inadvertent as it may have been, utilizing anthropology in this role in public health often inherently used techniques of "victim blaming - that is, seeing the poor health of a population as the sole result of its culture, instead of looking also at their particular economic or social situation" (Helman 5). Farmer further elaborated on this issue:

Scholars often weaken their
contributions to an understanding
of infectious diseases by making
"immodest claims of causality." These
claims are immodest because they are
wrong or misleading. They are immodest
because they distract attention from the
modest interventions that could treat
and often enough cure people. And they
are immodest because they distract
attention from the preventable social
disorder that exacerbates biological
disorder. (5)

Clearly, there was a need for the anthropology of public health to adopt a similar perspective to that of critical medical anthropology. Van Willigen defines a dichotomy between 'anthropology in policy' and 'anthropology of policy' (164). This semantic technicality differentiates between anthropologists who assist policy makers (reminiscent of clinically applied anthropology) and those who critically appraise the work of policy makers and their policies' unintended negative effects upon the target population. Parker and Harper describe the anthropology of public health as that "which remains passionately concerned about ill-health and deprivation and the need for public policy; but also remains committed to a rigorous and critical analytical perspective" (2).

With its new critical and reflexive perspective, anthropology has a lot to contribute to the development of health policy. The field of public health - and more generally, policy development requires research contributions from a multitude of disciplines. Williams states that "a multidisciplinary approach could best address the public health needs of a population" (Williams 1).

Public health's primary concern is to improve the health of a population. This broadscope approach has brought epidemiology to be the most influential discipline in health policy because by using methodical sampling methods one can theoretically extrapolate conclusions about the state of health of entire populations. Turnock states that there are "five basic sciences of public health: epidemiology, biostatistics, environmental science, management sciences and behavioural sciences" (20). 
It would seem that despite great anthropology's potential for informing health policy, its actual contribution is quite small - seeing that it is grouped with a half-dozen behavioural sciences as one of the five informants of policymaking. The reason for anthropology's minimized role in health policy development is likely founded in its primary methodological approach: ethnography. Thanks to an unabashed focus on individuals and small groups, many involved in the process of policymaking have argued that the data that generated by anthropological research is less valuable because it does not lend itself to broad 'scientific' extrapolation, as does epidemiological data. Ethnographic research involves observing and conducting interviews with a small group of people. With such small numbers, it is possible to argue that these individuals could easily be unrepresentative of the general population.

Despite the uphill battle that faces anthropologists in the public health sector, it is imperative to continue the work, as ethnographic inquiry has the potential to generate a great deal of rich information which can influence policy development. In the following section, I will describe four ways anthropology can influence public health policy in ways that epidemiology or other methods cannot. (A) The ability to see culture in its proper context in the social world and how culture affects all research. (B) The ability to pick up on minute and seemingly irrelevant details. (C) Independence from biomedical goals and hegemony allows medical anthropologists to add a critical voice to the public health discourse. (D) Provision of objective, qualitative data in an otherwise quantitative field.

\section{WHAT DOES ANTHROPOLOGY BRING TO PUBLIC HEALTH POLICY DEVELOPMENT?}

\section{A - Integrated Perspective of Culture}

When striving to understand disease etiology among a given population, public health specialists and human ecologists often use a 'multifactorial model of disease' (Curnow and Smith). This is a model in which there are a number of distinct factors that are thought to contribute to disease in the population. Culture is one of these factors, alongside many others, including: genetics, environment and so forth. The factorial model seems consistent with earlier medical anthropological research, relating to the method of the clinically applied anthropologist. By involving anthropologists on a clinical level it is possible to reduce the impact of the culture 'factor' on disease prevalence.
Many medical anthropologists see this model of disease as outdated and inaccurate because "it reduces the investigation of social and cultural aspects of disease to discrete, static, quantifiable 'beliefs' held by the study population" (Parker and Harper 1-2). This factorial notion of disease seems to involve the reasoning that factors of disease causation such as biology and environment are beyond the reach of culture. A modern conception of culture, as accepted by most anthropologists is significantly more complex and all-encompassing. In contemporary medical anthropology, it is believed that all research, even the most subjective and scientific, is rooted in the culture and experience of those who interpret and publish the results.

As a result of past discussions and debates within the field, contemporary medical anthropology is equipped to see beyond the established factorial model of disease. Similar discussions have taken place in medical anthropology such as those surrounding the Cartesian dualism paradigm. This is a dichotomy between the mind and the body of an individual. This worldview is characterized by a mechanistic view of disease etiology, very similar to that in the factorial model. The Cartesian paradigm continues to be used in western biomedicine and was accepted in medical anthropology for many years. Only recently, under the context of the 'new' critical version of medical anthropology, has this concept come under the microscope. Scheper-Hughes and Lock argue for the need to problematize such a seemingly simple dualism. They claim that it is not as straightforward an issue as it may seem. They challenge "medical anthropologists and clinicians to view humans and the experience of illness and suffering from an integrated perspective" (ScheperHughes and Lock 10).

While it may be argued that clinicians have held on to "the Cartesian Legacy," anthropologists have been working for years at developing such an integrated perspective. Medical anthropologists can contribute significantly to public health policy by providing this perspective to aid by providing an alternative to the entrenched factorial model of disease in the world of public health.

\section{$B-$ Holism}

The new medical anthropology's "inclusion of 'the whole"' (Porter 139) is another important tool that has the potential to be of great use in policy development. Anthropology is involved in seeing the entire situation in a given community. This involves participant observation in order to capture the smallest details in the events of individuals' 
lives. This also involves study of the macro-level forces and structures that are acting on people that cause them to behave the way they do.

The importance of anthropology's holism also relates to dispelling the notion of the factorial model. The factorial model sees culture in isolation from all other factors. This type of reasoning can lead to what Helman calls 'victim blaming'. The same pattern can be observed in public health policy if culture is considered isolated from political, social and economic factors. Heald provides an example from her research on HIVIAIDS policy in Botswana:

Little money was pledged to
the development of medical
infrastructures... instead, a dangerously
infectious disease was combated only
by programmes that urged individuals to
try and avoid it as best as they could in
a situation where there was no means of
knowing who was infected and who was
not and, in the main, no way of finding
out (30).

Maintaining input from an anthropological perspective is important in order to avoid this kind of counter-productive policy being developed. It is important to utilize a holistic approach to illness in order to identify all pertinent factors that contribute to a given pandemic. John Porter, an epidemiologist, has said of anthropology: "The discipline concentrates on what is actually happening and looks to 'the root' of where things come from" (Porter). Whether this 'root' at the level of social interactions between individuals, a cultural nuance or the macrocosmic structures that impact a given population, anthropological methods of investigation have proven reliable in identifying it.

\section{C-Critical Perspective}

The third feature unique to the new medical anthropology making it a valuable contributor to public health practice is its freedom from the theories and views of western biomedicine. Biomedicine, epidemiology and the other contributing sciences are inherently reductionist and hence have a very narrow scope in which to view the phenomenon of illness or epidemic. Everything is expected to have an explanation grounded in biology or 'science'.

One of the distinguishing features of the new medical anthropology is its tendency to be critical - especially of the hegemonic structure of biomedicine. Scheper-Hughes states that: "our work should be at the margins, questioning premises, and subjecting epistemologies that represent powerful, political interests to oppositional thinking" ("Three Propositions" 196). This type of oppositional thinking is important in generating new theories and in promoting necessary discourse to effectuate much needed change in public health systems.

To this day, one often hears allegations against anthropology for its past as the 'handmaiden' of colonialism. As a result of having to defend itself from these claims, the discipline has become very critical of hegemonic power structures that are involved in neo-colonial oppression of the afflicted and underprivileged. Biomedicine is a classic example of such a potentially oppressive structure. Several accounts exist that describe how "the doctor has replaced the priest as the custodian of social values" (Turner 37-38). For example, one author writes a detailed account of how the Public Health institution in the Philippines functions as an emissary of the state in subjecting people to foreign practices in order to effectuate control and domination over the public (Anderson). Anthropology's inward looking critical perspective of medicine and public health makes the data that it generates very important to the development of further policy. Scheper-Hughes states that it is "imperative to position ourselves squarely on the side of human suffering" ("Three Propositions" 196). Anthropologists have gone from being the handmaidens of colonial power to advocates for the afflicted and suffering. Many of the other sciences that contribute to health policy share biomedicine's mechanistic paradigm. Criticism is necessary to stimulate improvements in structures or programs that are already firmly entrenched. Critical medical anthropology is able to provide this unique perspective to the field of public health.

In order to remain in a good position to criticique biomedicine, it is important that anthropology maintain its distance from the biases and philosophies of western medicine. Many medical anthropologists remain critical of anthropological research that is funded by interests vested in biomedicine. This type of funding arrangement prohibits a fully critical interpretation and thus "compromises what anthropology has to offer as a discipline" (Parker and Harper 2).

\section{D - Qualitative Analysis}

The fourth significant contribution that anthropology makes to the development of public health policy is its qualitative approach to data collection. This is also unique to anthropology among all of the sciences that inform public health policy. The qualitative methodology of ethnography separates 
anthropology from all of the natural sciences and many of the social sciences. Ian Hacking explains why qualitative data is so important in his critique of statistical data: "The fetishistic collection of overt statistical data about a population has as its motto 'information and control' but it would more truly be 'disinformation and mismanagement"' (280). His premise is that quantitative analysis requires extensive categorization. Many of the categories that are used are in essence constructs of the investigators and do not even exist in the worldview of the informant. This creates a false perception of reality in the minds of policymakers that cannot be avoided through structured, quantitative analysis.

A similar critique was voiced by Parker and Harper, about supposed qualitative research conducted by many traditionally quantitativelyoriented social scientists.

Heavy reliance upon pre-designed questions, combined with spending limited periods of time in the field, inevitably structures the 'qualitative' in terms defined by the researcher rather than the researched; and this may well be at the expense of understanding the very people they seek to assist (3).

True ethnographic data strives to sidestep these misunderstandings and misrepresentations by coming to an understanding of the worldviews of its participants. This is in contrast traditional public health research, which imposes a foreign view upon informants, or counts them and in doing so categorizes them into culturally constructed groups that support the researchers' own agenda. Harper states: "one of the best ways to understand a situation is to spend extended periods of time interacting with those involved" (59). Before appropriate policy can be developed it is crucial to gain a solid understanding of the situation and more importantly, how those affected think and feel about the situation. This understanding can only be gained through ethnographic inquiry.

Porter explains the importance of qualitative ethnographic research in policy development through the use of the statistical concept of the outlier. He states that as an epidemiologist, outliers skew data in ways that don't seem to make sense. Therefore oftentimes epidemiologists will seek for rational, explainable reasons to exclude outliers from datasets. He goes on to explain that it is important to look "for ways of supporting the outlier to speak" (140). He has found that narratives derived through qualitative anthropological research methodologies allow him to discover this voice - the voice of "those who are normally unheard in the current international political climate" (139).

\section{THE APPLICATION OF CMA TO PUBLIC HEALTH RESEARCH}

Thus far, this article has sought to underscore the importance of the development of the critical perspective in medical anthropology. As has been described above, this is a crucial component of medical anthropology's contribution to public health.

Despite anthropology's strengths outlined above, a common critique of CMA is that it is overly idealized and not in line with the realities of the world. However, Peacock states that "pragmatism and searching critique need not be mutually exclusive" (12). Rylko-Bauer et al. contend that anthropology's future viability as a discipline lies in its ability to continue applying critical notions in the formulation of pragmatic solutions. They claim that "practice is part of the discipline's destiny and needs to be at the centre of discussions about anthropology's future" (187). They not only stress how important it is for anthropology to take a practical stance, but further elaborate how such is possible:
A meaningful convergence of methodologically sound, critical, reflexive, and engaged anthropology - a convergence that builds on and learns from the extensive past experience of putting anthropology to use - will free us up to focus on differences that actually do matter in the real world. (187)

The discipline of public health is at the point of making a major decision, largely because of a publication known as the Black Report, which showed a very strong correlation between the income and health of a population (Hamlin).

Public health remains at a crossroads. The choice is between a narrow focus on health service issues and the health problems of individuals on the one hand, or a refocus on the major underlying causes of population health on the other. (Beaglehole and Bonita 2-3)

Anthropology is well-positioned to play a key role in the informing of health policy to address these issues. This article has focused on the 
changes that have occurred in medical anthropology and the anthropology of public health that allow it to be a modern and significant contributing discipline to public health policy development. Critical medical anthropology has the potential to be a great force towards informing public health policy that is focused on the macro-level underlying causes of poor health in a population. Anthropology's distinct character as integrated, critical, holistic and qualitative makes it a very potent force in encouraging public health policy in a similarly critical direction.

\section{REFERENCES}

Anderson, Warwick. "Excremental Colonialism: Public Health and the Poetics of Pollution." Critical Inquiry 213 (1995): 640-69. Print.

Baer, Hans. "The Possibilities and Dilemmas of Building Bridges between Critical Medical Anthropology and Clinical Anthropology: A Discussion." Social Science of Medicine 309 (1990): 1011-13. Print.

Beaglehole, R, and R Bonita. Public Health at the Crossroads: Achievements and Prospects. Cambridge: Cambridge University Press, 2004. Print.

Butt, L. "The Suffering Stranger: Medical Anthropology and International Morality." Medical Anthropology 21 (2002a): 1-24. Print.

Chrisman, N, and T Maretzki. Clinicially Applied Anthropology. New York: Springer, 1982. Print.

Curnow, R, and C Smith. "Multifactorial Model for Familial Diseases in Man." Journal of the Royal Statistical Society 1382 (1975): 13169. Print.

Farmer, Paul. Infections and Inequalities: The Modern Plagues. Berkeley, CA: University of California Press, 1999. Print.

Hacking, lan. "Biopower and the Avalanche of Printed Numbers." Humanities in Society 5 (1982): 279-95. Print.

Hamlin, Christopher. "The History and Development of Public Health in Developed Countries." Oxford Textbook of Public Health: The Scope of Public Health. Eds. Daniels, R, et al. Vol. 1. Oxford: Oxford University Press, 2002. Print.

Harper, I. "Anthropology, Dots and Understanding Tuberculosis Control in Nepal." Journal of Biosocial Sciences 38 (2006): 57-67. Print.

Heald, S. "Abstain or Die: The Development of Hiv/Aids Policy in Botswana." Journal of Biosocial Sciences 38 (2006): 29-41. Print.

Helman, Cecil. Culture, Health and IIIness. 2007. Print.

Irwin, Alec, et al. "Suffering, Moral Claims and Scholarly Responsibility: A Response to Leslie Butt." Medical Anthropology 21 (2002): 25-30. Print.
Kim, J, et al. Dying for Growth: Global Inequality and the Health of the Poor. Monroe, ME: Common Courage Press, 2000. Print.

Kleinman, Arthur. "Concepts and a Model for the Comparison of Medical Systems as Cultural Systems." Social Science and Medicine 12 (1978): 85-93. Print.

Lewis. "The Misrepresentation of Anthropology and Its Consequences." American Anthropologist 1003 (1998): 716-31. Print.

McElroy, A. "Medical Anthropology." Encyclopedia of Cultural Anthropology. Eds. Levinson, D and M Ember. New York: Henry Holt, 1996. Print.

Parker, M., and I. Harper. "The Anthropology of Public Health." Journal of Biosocial Sciences 38 (2005): 1-5. Print.

Peacock, James. "The Future of Anthropology." American Anthropologist 991 (1997): 9-17. Print.

Pels, Peter, and Oscar Salemind. "Introduction." Colonial Subjects: Essays on the Practical History of Anthropology. Eds. Pels, Peter and Oscar Salemind. Ann Arbor, Ml: University of Michigan Press, 1999. Print.

Porter, J.D.H. "Epidemiological Reflections of the Contribution of Anthropology to Public Health Policy and Practice." Journal of Biosocial Sciences 38 (2006): 133-44. Print.

Rylko-Bauer, B., M Singer, and J Van Willigen. "Re-Claiming Applied Anthropology: Its Past, Present and Future." American Anthropologist 1081 (2006): 178-90. Print.

Scheper-Hughes, Nancy. "Coming to Our Senses: Cultural Anthropology at the Millenium." Teaching Anthropology 72 (2000): 8-13. Print.

---. "Three Propositions for a Critically Applied Medical Anthropology." Social Science in Medicine 302 (1990): 189-97. Print.

Scheper-Hughes, Nancy, and Margaret Lock. "The Mindful Body: A Prolegomnon to Future Work in Medical Anthropology." Medical Anthropology Quarterly 1 (1987): 6-41. Print.

Turner, B. Medical Power and Social Knowledge. London: Routledge, 1987. Print.

Turnock, Bernard J. Public Health: What It Is and How It Works. Boston: Jones and Bartlett Publishers, 2004. Print.

Van Willigen, J. Applied Anthropology: An Introduction. Westport, CT: Greenwood, 2002. Print.

Williams, Holly Ann. "Caring for Those in Crisis: Integrating Anthropology and Public Health in Complex Humanitarian Emergencies." National Association for the Practice of Anthropology Bulletin 144 (2001): 1-16. Print. 